\title{
Analysis of 5-aminolevulinic acid-induced fluorescence in 55 different spinal tumors
}

\author{
Matthias Millesi, M.D., ${ }^{1,3}$ Barbara Kiesel, M.D., ${ }^{1,3}$ Adelheid Woehrer, M.D., Ph.D., ${ }^{2,3}$ \\ Johannes A. Hainfellner, M.D., ${ }^{2,3}$ Klaus NovaK, M.D., ${ }^{1}$ \\ Mauricio Martínez-Moreno, M.D., 1 Stefan Wolfsberger, M.D., 1,3 \\ Engelbert Knosp, M.D., ${ }^{1,3}$ And Georg Widhalm, M.D., Ph.D., ${ }^{1,3}$ \\ ${ }^{1}$ Department of Neurosurgery, ${ }^{2}$ Institute of Neurology, and ${ }^{3}$ Comprehensive Cancer Center-Central Nervous \\ System Tumours Unit, Medical University of Vienna, Austria
}

Object. Subtotal resection (STR) of spinal tumors can result in tumor recurrence. Currently, no clinically reliable marker is available for intraoperative visualization of spinal tumor tissue. Protoporphyrin IX (PpIX) fluorescence induced by 5-aminolevulinic acid (5-ALA) is capable of visualizing malignant gliomas. Fluorescence-guided resections of malignant cerebral gliomas using 5-ALA have resulted in an increased rate of complete tumor removal. Recently, the application of 5-ALA has also been described in the first cases of spinal tumors. Therefore, the aim of this observational study was to systematically investigate 5-ALA-induced fluorescence characteristics in different spinal tumor entities.

Methods. Three hours before the induction of anesthesia, 5-ALA was administered to patients with different intra- and extradural spinal tumors. In all patients a neurosurgical resection or biopsy of the spinal tumor was performed under conventional white-light microscopy. During each surgery, the presence of PpIX fluorescence was additionally assessed using a modified neurosurgical microscope. At the end of an assumed gross-total resection (GTR) under white-light microscopy, a final inspection of the surgical cavity of fluorescing intramedullary tumors was performed to look for any remaining fluorescing foci. Histopathological tumor diagnosis was established according to the current WHO classification.

Results. Fifty-two patients with 55 spinal tumors were included in this study. Resection was performed in 50 of 55 cases, whereas 5 of 55 cases underwent biopsy. Gross-total resection was achieved in 37 cases, STR in 5 , and partial resection in 8 cases. Protoporphyrin IX fluorescence was visible in $30(55 \%)$ of 55 cases, but not in 25 (45\%) of 55 cases. Positive PpIX fluorescence was mainly detected in ependymomas (12 of 12), meningiomas (12 of 12), hemangiopericytomas ( 3 of 3 ), and in drop metastases of primary CNS tumors ( 2 of 2$)$. In contrast, none of the neurinomas ( 8 of 8), carcinoma metastases ( 5 of 5 ), and primary spinal gliomas ( 3 of $3 ; 1$ pilocytic astrocytoma, 1 WHO Grade II astrocytoma, 1 WHO Grade III anaplastic oligoastrocytoma) revealed PpIX fluorescence. It is notable that residual fluorescing tumor foci were detected and subsequently resected in 4 of 8 intramedullary ependymomas despite assumed GTR under white-light microscopy.

Conclusions. In this study, 5-ALA-PpIX fluorescence was observed in spinal tumors, especially ependymomas, meningiomas, hemangiopericytomas, and drop metastases of primary CNS tumors. In cases of intramedullary tumors, 5-ALA-induced PpIX fluorescence is a useful tool for the detection of potential residual tumor foci. (http://thejns.org/doi/abs/10.3171/2013.12.FOCUS13485)

\section{Key Words • spinal tumor • 5-ALA • PpIX fluorescence • residual fluorescing tumor}

$\mathrm{S}$ PINAL neoplasms account for 4\%-8\% of all CNS tumors. ${ }^{11}$ Based on their site of origin, such neoplasms occur either as epidural or intradural (extramedullary or intramedullary) tumors..$^{3,6,11,21,24,25,30,39,42}$ The histopathological diagnosis of spinal neoplasms is routinely

\footnotetext{
Abbreviations used in this paper: 5-ALA $=5$-aminolevulinic acid; GTR = gross-total resection; MEP = motor evoked potential; $\mathrm{PpIX}=$ protoporphyrin IX; PR = partial resection; STR = subtotal resection.
}

established according to the WHO criteria, and specific tumor entities show preferred spinal compartments: The most common tumor entities found intradurally are meningiomas $(29 \%)$, nerve sheath tumors $(24 \%)$, ependymomas (23\%), and astrocytomas (6\%)..$^{9,11,18,31}$ In contrast, the most frequent tumor mass in the epidural compartment results from metastatic disease..$^{3,11,21,24}$ Currently, the primary treatment of choice for the majority of spinal tumors is gross-total resection (GTR) with preservation of neurological function. . $^{611,25,30,39,42}$ 
In routine clinical practice, however, subtotal resection (STR) of spinal tumors is not uncommon..$^{9,11,31}$ In fact, STR is observed in up to $44 \%$ of intramedullary ependymomas despite their usually well-circumscribed growth pattern and in up to $94 \%$ of diffusely infiltrating astrocytomas. ${ }^{1,39}$ Such STRs result in tumor recurrence in up to $70 \%$ of cases. ${ }^{31,32}$ A common reason for STR is the premature termination of resection in response to significant deterioration in intraoperative neurophysiological monitoring. ${ }^{17,20,39}$ Another important explanation is remaining tumor tissue in the resection cavity that is generally not visible under the conventional microscope. ${ }^{17}$ Therefore, a clinically reliable technique for intraoperative visualization of spinal tumor tissue is warranted.

5-aminolevulinic acid (5-ALA) leads to intracellular accumulation of fluorescing protoporphyrin IX (PpIX) and is currently applied for fluorescence-guided resections of malignant gliomas within the brain. ${ }^{27,37}$ The application of 5-ALA has resulted in a higher rate of complete resections of malignant glioma than conventional procedures. ${ }^{34,35}$ Furthermore, 5-ALA has been used for the visualization of other brain tumor entities such as meningiomas and metastases as well. , $^{2,14,15,44}$ Recently, the use of 5-ALA was first reported in spinal tumors. So far, PpIX fluorescence has been observed in a few cases of ependymomas, meningiomas, and malignant gliomas. ${ }^{7,12,23,28,33}$ However, it remains unclear which specific histopathological spinal tumor entities can be visualized with 5-ALA-induced PpIX fluorescence.

Therefore, the aim of this observational study was to systematically analyze the frequency of 5-ALA-induced PpIX fluorescence in different intradural and extradural spinal tumor entities in a large patient series. Our data should define the histopathological spinal tumor entities that are potential candidates for intraoperative 5-ALA application and serve as a basis for future prospective studies.

\section{Methods}

5-ALA was administered to patients with different spinal intradural and extradural tumors surgically treated at the Department of Neurosurgery of the Medical University of Vienna. The local ethics committee approved this prospective study, and patients or their caregivers gave informed consent.

\section{Preoperative Imaging}

Preoperative MRI was performed within 4 weeks prior to surgery and included sagittal and axial T2- and T1-weighted MR sequences with and without contrast medium. All MRI investigations were conducted on a 1.5- or a 3-T clinical scanner.

\section{Surgery in Spinal Tumors}

Generally, all patients underwent a laminectomy or laminotomy before neurosurgical tumor removal or biopsy. To avoid postoperative neurological deterioration, intraoperative neurophysiological monitoring was performed. Our standard monitoring protocol included somatosensory evoked potentials (stimulation of the bilateral median and tibial nerves), muscle motor evoked potentials (MEPs) using transcranial electrical stimulation (recording from the abductor pollicis brevis, anterior tibial, and abductor hallucis muscles; optionally from additional segmental target muscles of the upper extremities), and epidural MEPs (direct [D]-wave), as described previously. ${ }^{26}$ Surgery was halted or modified if muscle MEPs changed or disappeared and stopped immediately if muscle MEPs were lost and Dwave amplitude decreased to less than $50 \%$ of the baseline value. ${ }^{30}$

\section{5-ALA in Spinal Tumor Surgery}

Oral solutions of 5-ALA (20 mg/kg body weight) were administered 3 hours before induction of anesthesia in all patients. For intraoperative visualization of 5-ALAinduced PpIX fluorescence, we used a modified neurosurgical microscope (NC4 and Pentero, Carl Zeiss Surgical $\mathrm{GmbH}$ ) with the ability to switch to violet-blue excitation light. ${ }^{36}$ During the tumor resection or biopsy, the following specific aspects were analyzed: 1) The PpIX fluorescence status in each tumor was checked and documented as PpIX positive ("strong" or "vague") or negative, as described previously. ${ }^{43-45}$ During the resection or biopsy, we did not perform a fluorescence-guided tumor resection with the removal of PpIX-positive tumor tissue under violet-blue excitation light. 2) The homogeneity of PpIX fluorescence was analyzed in all fluorescing tumors and documented as a homogeneous or inhomogeneous fluorescence pattern. If an inhomogeneous PpIX fluorescence effect was detected within the tumor, separate specimens were taken from fluorescing and nonfluorescing tumor areas for histopathological analysis whenever possible. 3) As small residual tumor foci can be missed during resection of intramedullary tumors in particular, the resection cavity in such tumors was investigated for any remaining PpIX fluorescence at the end of an assumed GTR under conventional white-light microscopy. In cases with a remaining fluorescing focus, the PpIX-positive tissue was removed using intraoperative neurophysiological monitoring and collected for histopathological analysis.

After surgery, all patients were protected from light sources for 24 hours given the possible phototoxic effects of 5-ALA.

\section{Histopathological Analysis}

The local neuropathology team routinely processed all tumor samples for histopathological workup (formalin fixation and paraffin embedding) and established the histopathological diagnosis according to current WHO criteria. ${ }^{18}$ The neuropathologists were blinded to the intraoperative PpIX fluorescence status of each tumor sample.

Furthermore, in cases of an inhomogeneous PpIX fluorescence pattern, the tumor cell proliferation rate was assessed in fluorescing and nonfluorescing tumor specimens. An MIB-1 antibody kit (anti-Ki 67, 1:50, DAKO) was applied, and in each specimen a total of 500 tumor cell nuclei were evaluated in hot spots, as described previously. ${ }^{43-45}$

Finally, all tissue samples derived from a remaining PpIX fluorescing focus were histopathologically screened for the presence of tumor tissue. 


\section{Postoperative Imaging and Neurological Follow-Up}

Generally, MRI was performed within 72 hours after surgery, especially for intramedullary tumors and if clinically indicated or required before initiation of postoperative adjuvant therapy. In other cases, the first postoperative MRI study was routinely conducted 3 months after surgery. Extent of resection was assessed according to the following modified criteria initially proposed by Klekamp: ${ }^{16}$ 1) GTR, no residual tumor on postoperative MRI; 2) STR, complete removal of the spinal neoplasm with a small residual tumor on postoperative MRI; 3) partial resection (PR), incomplete removal of the spinal neoplasm verified by postoperative MRI; and 4) biopsy, reduction of the tumor mass less than $50 \%$.

To detect any new postoperative deficits, all patients were examined neurologically, and their status according to the McCormick scale was graded at the time of discharge and compared with the preoperative grade (Table 1). ${ }^{19,30}$

\section{Statistical Analysis}

For statistical analysis, we used SPSS version 20.0 statistical software (SPSS Inc.). The proliferation rate between fluorescing and nonfluorescing samples was compared using a paired Student t-test. A p value $<0.05$ was considered statistically significant.

\section{Results}

5-ALA was administered to 52 patients with different spinal intra- and extradural tumors prior to surgery. We systematically investigated the intraoperative 5-ALA-induced PpIX fluorescence characteristics in the different histopathological spinal tumor entities. The application of 5-ALA during spinal neurosurgical procedures was feasible in all cases, and no relevant side effects occurred after administering the compound.

\section{Patient Characteristics}

In the 52 patients ( 30 females, 22 males) 55 spinal tumors were treated neurosurgically. In 2 of these patients, multiple spinal tumors were treated: In the first patient, 2 different tumors (1 meningioma [Case 6] and 1 ependymoma [Case 41]) at the same cervical level were removed in one procedure (Fig. 1). The second patient underwent surgery twice because of multiple spinal hemangiopericytomas (Cases 26-28). For further patient characteristics see Tables 2 and 3.

\section{Neurosurgical Procedures for Spinal Tumors}

All neurosurgical procedures were performed under conventional white-light microscopy. Intraoperative neurophysiological monitoring was applied in 15 of 31 cases of intradural extramedullary lesions if indicated and in all intramedullary tumors $(\mathrm{n}=19)$. Among the 55 spinal tumors, resection was performed in 50 cases (91\%); in 5 cases ( $9 \%$ ), a biopsy was performed.

According to the first available postoperative MRI study, GTR was achieved in 37 of the resected cases (74\%), STR in $5(10 \%)$, and PR in $8(16 \%)$. The major reason for incomplete resection (13 cases) was a diffuse infiltrative growth pattern in 6 cases $(46 \%)$, the absence of a clear cleavage plane in 3 cases $(23 \%)$, a significant decrease in the amplitude of muscle and epidural MEPs (D-wave) in 2 cases (15\%), and an extraspinal extension of the tumor in the remaining 2 cases $(15 \%)$. Further details are provided in Tables 2 and 3.

\section{Histopathological Analysis: WHO Tumor Diagnosis}

Histopathological analysis of all spinal tumors revealed meningioma in 12 cases, ependymoma in 12 cases, neurinoma in 8 cases, and carcinoma metastasis in 5 cases. Furthermore, primary spinal glioma was diagnosed in 3 cases (1 pilocytic astrocytoma, 1 WHO Grade II astrocytoma, 1 WHO Grade III anaplastic oligoastrocytoma) and hemangiopericytoma in 3 cases. A complete list of the different tumor entities, as well as their WHO grade and subtype, is provided in Table 3.

\section{Intraoperative PpIX Fluorescence Characteristics of Spinal Tumors}

Fluorescence Status. Using violet-blue excitation light, we observed PpIX fluorescence in 30 (55\%) of 55 spinal tumors. This fluorescence was classified as "strong" in 28 of these tumors (93\%) and "vague" in 2 cases (7\%). In contrast, no fluorescence was observed in 25 neoplasms (45\%).

All ependymomas (Fig. 1), meningiomas (Figs. 1 and 2), hemangiopericytomas and drop metastases of primary CNS tumors showed positive PpIX fluorescence. In contrast, no PpIX fluorescence was detected in any of the neurinomas (Fig. 3), carcinoma metastases, and primary spinal gliomas (1 pilocytic astrocytoma, 1 WHO Grade II astrocytoma, 1 WHO Grade III anaplastic oligoastrocytoma). The histology of each spinal tumor and the corresponding PpIX fluorescence status are listed in Table 3.

Fluorescence Homogeneity. Among the 30 fluoresc-

TABLE 1: McCormick scale

\begin{tabular}{cc}
\hline Grade & Definition \\
\hline I & $\begin{array}{c}\text { neurologically normal; mild focal deficit not significantly affecting function of involved limb; mild spasticity or reflex } \\
\text { abnormality; normal gait }\end{array}$ \\
II & $\begin{array}{c}\text { presence of sensorimotor deficit affecting function of involved limb; mild to moderate gait difficulty; severe pain or } \\
\text { dysesthetic syndrome impairing patient's quality of life; still functions \& ambulates independently }\end{array}$ \\
III & more severe neurological deficit; requires cane/brace for ambulation or significant bilat upper extremity impairment; \\
& may or may not function independently
\end{tabular}





FIG. 1. Cases 6 and 41. Visualization of a spinal meningioma and ependymoma with 5-ALA-induced PpIX fluorescence in a patient with neurofibromatosis Type II. Preoperative contrast-enhanced T1-weighted MR images (A and B) reveal an intramedullary tumor (WHO Grade II ependymoma, white arrow) as well as an intradural extramedullary lesion (WHO Grade I meningioma, black asterisk) at the C6-7 level. After myelotomy the grayish tumor tissue of the ependymoma under conventional white-light (C) can be visualized by strong and homogeneous PpIX fluorescence under violet-blue excitation light (D). After assumed GTR through conventional tumor removal (E), a small remaining fluorescing focus (black arrow) was identified in the resection cavity under violet-blue excitation light (F). This remaining fluorescing focus corresponded histopathologically to ependymoma tissue (G) with an increased proliferation rate $(\mathrm{H})$. Additionally, the typical meningioma tissue during conventional white-light resection (I) shows strong PpIX fluorescence under violet-blue excitation light (J). Postoperative MR images (K and L) demonstrate GTR of the spinal ependymoma as well as the meningioma. $H \& E(G)$ and anti-Ki $67(H)$, original magnification $\times 20$.

ing spinal tumors, we found a homogeneous fluorescence pattern in $20(67 \%)$ neoplasms, whereas 10 lesions $(33 \%)$ showed an inhomogeneous fluorescence effect with fluorescing and nonfluorescing areas within the same tumor. A homogeneous PpIX fluorescence pattern was observed in 10 of 12 meningiomas, 5 of 12 ependymomas, all 3 hemangiopericytomas, and the 2 drop metastases of primary CNS tumors. In contrast, histopathological tumor entities showing an inhomogeneous PpIX fluorescence pattern included 7 of 12 ependymomas, 2 of 12 meningiomas, and 1 ganglioglioma (Fig. 4). Additionally, we assessed the proliferation index (MIB-1) in fluorescing and nonfluorescing areas within the same tumor whenever distinct specimens were available (6 of 10 cases: 4 ependymomas and 2 meningiomas). We observed a higher mean proliferation rate in PpIX-positive as compared with PpIX-negative areas (MIB-1: 6.7\% vs 1.5\%,p $=0.77$ ). Further details on each patient concerning PpIX fluorescence homogeneity are provided in Table 3.

\section{Protoporphyrin IX Fluorescence at the End of Resection}

At the end of tumor removal, we inspected the resection cavity for any remaining PpIX fluorescence in 8 of 12 fluorescing intramedullary tumors (all ependymomas) with assumed GTR under white-light microscopy: In 4 of these 8 cases, remaining fluorescing foci were detected and subsequently resected with the aid of intraoperative neurophysiological monitoring (Fig. 1). In none of these cases did evoked potentials deteriorate. Gross-total resection was verified with early postoperative MRI in all of these cases. Histopathological assessment revealed the distinct tumor tissue of an ependymoma in each sample of remaining fluorescence.

In the remaining 4 cases of fluorescing intramedullary tumors, GTR could not be achieved given the absence of a clear cleavage plane in 3 cases and a significant deterioration in MEPs in 1 case.

\section{Neurological Status}

In the preoperative neurological examination, no or only minor deficits (McCormick Grades I and II) were found in 36 patients $(69 \%)$, whereas 16 patients $(31 \%)$ showed major deficits (McCormick Grades III and IV). At the time of discharge, neurological function remained unchanged in 36 patients (69\%). An improvement in the postoperative McCormick grade was noted in 6 patients (12\%). In contrast, deterioration in neurological function occurred in 10 patients (19\%). Postoperative deterioration 
TABLE 2: Summary of characteristics in 52 patients with spinal tumors

\begin{tabular}{lc}
\hline \multicolumn{1}{c}{ Parameter } & No. (\%) \\
\hline no. of patients & 52 \\
no. of spinal tumors (\%) & $55(100)$ \\
female:male ratio & $1.4: 1$ \\
median age in yrs (range) & $48(17-87)$ \\
segment (\%) & \\
thoracic & $30(54)$ \\
cervical & $18(33)$ \\
lumbar & $6(11)$ \\
sacral & $1(2)$ \\
compartment & \\
intradural/extramedullary & $31(56)$ \\
intramedullary & $19(35)$ \\
extradural & $5(9)$ \\
extent of resection* & \\
GTR & $37(67)$ \\
STR & $5(9)$ \\
PR & $8(15)$ \\
biopsy & $5(9)$ \\
\hline
\end{tabular}

* Extent of resection was assessed on the first available postoperative MR image.

occurred in 2 cases as a result of rapid malignant tumor progression. In another case, spinal ischemia occurred because of injury to the anterior spinal artery, leading to an immediate postoperative severe functional deficit with continuous recovery in the follow-up. In the remaining cases, impairment of neurological function mainly occurred in tumors with an infiltrative growth pattern or no clear cleavage plane. A complete list of pre- and postoperative McCormick grades is listed in Table 4.

\section{Discussion}

In the present observational study, we systematically investigated the 5-ALA-induced PpIX fluorescence characteristics in different spinal intra- and extradural tumor entities. According to our data, PpIX fluorescence appears in spinal tumors, particularly in ependymomas, meningiomas, hemangiopericytomas, and drop metastases of primary CNS tumors. Furthermore, PpIX fluorescence is a powerful tool for detecting residual tumor tissue in intramedullary tumors.

\section{Importance of GTR and Drawbacks}

Several studies have demonstrated that GTR of spinal tumors represents the most important predictor of prolonged progression-free survival. ${ }^{32}$ Consequently, GTR using intraoperative neurophysiological monitoring is the treatment of choice in the majority of patients. ${ }^{30,39}$ However, incomplete resection of spinal tumors is not uncommon in routine clinical practice..$^{9,11,31}$ In this sense, STR rates as high as $44 \%$ in intramedullary ependymomas and $94 \%$ in diffusely infiltrating astrocytomas have been reported in the literature., ${ }^{1,39}$ One factor leading to STR is the premature termination of resection in response to a deterioration in evoked potentials, to prevent new neurological deficits. ${ }^{17,20,39}$ Precise differentiation of tumor from surrounding tissue represents another significant difficulty in achieving GTR. This inability to distinguish between the two tissue types may lead to small tumor residues within the resection cavity that are frequently not visible under conventional white-light microscopy. For example, Kucia et al. described 2 cases of intramedullary ependymomas in which GTR was achieved intraoperatively, but postoperative MRI revealed small residual tumor foci.${ }^{17}$ Furthermore, the absence of a clear cleavage plane is another reason for STR, mainly in diffusely infiltrating tumors such as astrocytomas and in some ependymomas. ${ }^{10,12,20,46}$

To overcome these difficulties, intraoperative ultrasound has been established as a powerful technique for precise localization of spinal tumors and thus to increase rates of GTR. ${ }^{29,47}$ However, identification of tumor margins and residual tumors can rarely be accomplished using this technique. ${ }^{29,47}$ Therefore, innovative and clinically reliable tools for intraoperative visualization of spinal tumors are necessary to ensure GTR.

\section{Fluorescence-Guided Procedures With 5-ALA in Neurosurgery}

Intraoperative visualization of tumor tissue through the application of photodynamic diagnosis using different fluorescent dyes in neurosurgery was reported as early as 1948. ${ }^{22}$ Since 1998, 5-ALA has evolved as the most widely used dye for fluorescence-guided procedures in neurosurgery..$^{38}$ This compound represents a precursor of heme biosynthesis that leads to the accumulation of fluorescing PpIX predominantly in malignant glioma tissue after oral administration..$^{27,37}$ Primarily, 5-ALA fluorescenceguided resections were performed in malignant gliomas to maximize tumor removal. ${ }^{34}$ In 2006, Stummer et al. conducted a multicenter Phase III trial on malignant gliomas comparing 5-ALA fluorescence-guided resections with conventional white-light procedures. ${ }^{35}$ These authors found a significantly higher frequency of complete resection of contrast-enhancing tumor and a prolonged progression-free survival in the 5-ALA group. Based on the promising data on this technique - that is, increasing the extent of resections in malignant gliomas-5-ALA was also used for visualizing nonglial brain tumors such as meningiomas and metastases. ${ }^{2,4,14,15,44}$ Recently, 5-ALA was applied for the intraoperative visualization of spinal tumors in single cases and two small studies. . $^{5,12,23,28,33}$ Protoporphyrin IX fluorescence was observed particularly in ependymomas, meningiomas, and malignant gliomas. Note, however, that a systematic analysis of the value of 5-ALA for intraoperative visualization of different intradural as well as extradural spinal tumors in a large patient series is still missing.

\section{5-ALA in Spinal Tumors}

During the neurosurgical resection or biopsy in our 
M. Millesi et al.

TABLE 3: Histological entities and fluorescence characteristics*

\begin{tabular}{|c|c|c|c|c|c|c|c|}
\hline Case & $\begin{array}{l}\text { Age (yrs) } \\
\text { Sex }\end{array}$ & Level & $\begin{array}{l}\text { Extent of } \\
\text { Resection }\end{array}$ & Histology & $\begin{array}{l}\text { WHO } \\
\text { Grade }\end{array}$ & $\begin{array}{l}\text { Fluorescence } \\
\text { Status }\end{array}$ & $\begin{array}{l}\text { Fluorescence } \\
\text { Homogeneity }\end{array}$ \\
\hline \multicolumn{8}{|c|}{ extradural } \\
\hline 1 & $58, M$ & $\mathrm{~T}-3$ & biopsy & metastasis (prostate carcinoma) & - & - & - \\
\hline 2 & $70, M$ & $\mathrm{~T}-11$ & PR & metastasis (rectum carcinoma) & - & - & - \\
\hline 3 & $44, \mathrm{~F}$ & T9-12 & biopsy & metastasis (mammary carcinoma) & - & - & - \\
\hline 4 & $54, \mathrm{M}$ & L5-S1 & PR & metastasis (prostate carcinoma) & - & - & - \\
\hline 5 & $38, \mathrm{M}$ & $\mathrm{C}-2$ & biopsy & giant cell tumor of bone & - & - & - \\
\hline \multicolumn{8}{|c|}{ intradural extramedullary } \\
\hline $6 \dagger$ & 22, M & C6-7 & GTR & meningioma (not otherwise specified) & I & ++ & $\mathrm{h}$ \\
\hline 7 & $57, \mathrm{~F}$ & $\mathrm{~T} 12-\mathrm{L} 1$ & GTR & meningioma (meningothelial) & 1 & ++ & $\mathrm{h}$ \\
\hline 8 & $50, F$ & T8-9 & GTR & meningioma (meningothelial) & 1 & ++ & $\mathrm{h}$ \\
\hline 9 & $57, \mathrm{~F}$ & $\mathrm{~T}-11$ & GTR & meningioma (meningothelial) & I & ++ & $\mathrm{h}$ \\
\hline 10 & $66, \mathrm{M}$ & C3-5 & STR & meningioma (meningothelial) & I & ++ & $\mathrm{h}$ \\
\hline 11 & $81, \mathrm{~F}$ & T6-7 & GTR & meningioma (meningothelial) & 1 & ++ & $\mathrm{h}$ \\
\hline 12 & $56, \mathrm{~F}$ & T8-9 & GTR & meningioma (meningothelial) & 1 & ++ & $\mathrm{h}$ \\
\hline 13 & $73, \mathrm{~F}$ & T12-L1 & GTR & meningioma (meningothelial) & 1 & ++ & i \\
\hline 14 & $61, \mathrm{~F}$ & T11-12 & GTR & meningioma (psammomatous) & I & ++ & i \\
\hline 15 & $64, \mathrm{~F}$ & $\mathrm{~T}-11$ & GTR & meningioma (psammomatous) & 1 & ++ & $\mathrm{h}$ \\
\hline 16 & $72, \mathrm{~F}$ & T3-4 & GTR & meningioma (psammomatous) & 1 & ++ & $\mathrm{h}$ \\
\hline 17 & $83, \mathrm{~F}$ & T7-9 & GTR & meningioma (transitional) & 1 & ++ & $\mathrm{h}$ \\
\hline 18 & $45, \mathrm{~F}$ & $\mathrm{~T}-12$ & PR & neurinoma & I & - & - \\
\hline 19 & $29, \mathrm{M}$ & C-2 & PR & neurinoma & I & - & - \\
\hline 20 & $48, \mathrm{~F}$ & $\mathrm{~T} 10-11$ & GTR & neurinoma & I & - & - \\
\hline 21 & $22, \mathrm{M}$ & T5-6 & GTR & neurinoma & I & - & - \\
\hline 22 & $22, \mathrm{M}$ & T12-L1 & GTR & neurinoma & I & - & - \\
\hline 23 & $56, M$ & C6-7 & GTR & neurinoma & I & - & - \\
\hline 24 & $31, \mathrm{~F}$ & C-2 & GTR & neurinoma & I & - & - \\
\hline 25 & $51, \mathrm{~F}$ & L-3 & GTR & neurinoma & I & - & - \\
\hline $26 \ddagger$ & $33, \mathrm{M}$ & $\mathrm{T}-10$ & GTR & hemangiopericytoma & $\|$ & ++ & $\mathrm{h}$ \\
\hline $27 \ddagger$ & $35, M$ & C-3 & GTR & hemangiopericytoma & $\|$ & ++ & $\mathrm{h}$ \\
\hline $28 \ddagger$ & $35, M$ & C-7 & GTR & anaplastic hemangiopericytoma & III & ++ & $\mathrm{h}$ \\
\hline 29 & $61, \mathrm{M}$ & L4-5 & PR & chordoma & - & - & - \\
\hline 30 & $87, \mathrm{~F}$ & C3-4 & GTR & chordoma & - & - & - \\
\hline 31 & $42, F$ & T8-9 & GTR & $\begin{array}{l}\text { drop metastasis (papillary tumor of the } \\
\text { pineal gland) }\end{array}$ & $\|-I\|$ & ++ & $\mathrm{h}$ \\
\hline 32 & $28, M$ & $\mathrm{~s} 1-2$ & biopsy & drop metastasis (glioblastoma) & IV & ++ & $\mathrm{h}$ \\
\hline 33 & $20, M$ & terminal filum (L-3) & GTR & myxopapillary ependymoma & 1 & + & $\mathrm{h}$ \\
\hline 34 & $69, \mathrm{~F}$ & $\mathrm{~T} 1-4$ & PR & lipoma & I & - & - \\
\hline 35 & $34, \mathrm{M}$ & L1-S2 & biopsy & malignant peripheral nerve sheath tumor & $\|$ & - & - \\
\hline 36 & $28, M$ & L1-3 & GTR & paraganglioma & I & - & - \\
\hline \multicolumn{8}{|c|}{ intramedullary } \\
\hline 37 & $61, \mathrm{~F}$ & T-3 & STR & ependymoma & $\|$ & ++ & $\mathrm{i}$ \\
\hline 38 & $52, \mathrm{M}$ & C3-4 & GTR & ependymoma & ॥ & ++ & $\mathrm{i}$ \\
\hline 39 & $48, F$ & $\mathrm{~T}-12$ & GTR & ependymoma & $\|$ & ++ & i \\
\hline 40 & $32, \mathrm{~F}$ & T2-3 & GTR & ependymoma & II & ++ & $\mathrm{h}$ \\
\hline $41 \dagger$ & $22, \mathrm{M}$ & C6-7 & GTR & ependymoma & II & ++ & $\mathrm{h}$ \\
\hline 42 & $50, F$ & C5-6 & GTR & ependymoma & $\|$ & + & i \\
\hline 43 & $49, \mathrm{M}$ & $\mathrm{T}-8$ & GTR & ependymoma & II & ++ & $\mathrm{h}$ \\
\hline
\end{tabular}


5-ALA in spinal tumors

TABLE 3: Histological entities and fluorescence characteristics* (continued)

\begin{tabular}{|c|c|c|c|c|c|c|c|}
\hline Case & $\begin{array}{l}\text { Age (yrs), } \\
\text { Sex }\end{array}$ & Level & $\begin{array}{l}\text { Extent of } \\
\text { Resection }\end{array}$ & Histology & $\begin{array}{l}\text { WHO } \\
\text { Grade }\end{array}$ & $\begin{array}{c}\text { Fluorescence } \\
\text { Status }\end{array}$ & $\begin{array}{l}\text { Fluorescence } \\
\text { Homogeneity }\end{array}$ \\
\hline \multicolumn{8}{|c|}{ intramedullary (continued) } \\
\hline 44 & $40, \mathrm{~F}$ & C-3 & GTR & ependymoma & II & ++ & $\mathrm{h}$ \\
\hline 45 & $70, \mathrm{~F}$ & C7-T3 & STR & ependymoma & $\|$ & ++ & i \\
\hline 46 & $34, F$ & C2-7 & STR & ependymoma & II & ++ & $\mathrm{i}$ \\
\hline 47 & $72, \mathrm{~F}$ & T3-5 & GTR & anaplastic ependymoma & III & ++ & $\mathrm{i}$ \\
\hline 48 & $37, \mathrm{~F}$ & C2-6 & GTR & pilocytic astrocytoma & I & - & - \\
\hline 49 & $34, \mathrm{M}$ & $\mathrm{T} 7-8$ & PR & diffuse astrocytoma & $\|$ & - & - \\
\hline 50 & $27, \mathrm{~F}$ & T10-L1 & STR & anaplastic mixed oligoastrocytoma & III & - & - \\
\hline 51 & $45, \mathrm{M}$ & C3-4 & GTR & hemangioblastoma & I & - & - \\
\hline 52 & $34, \mathrm{M}$ & C4-5 & GTR & hemangioblastoma & I & - & - \\
\hline 53 & $17, \mathrm{~F}$ & C-1 & PR & ganglioglioma & I & ++ & i \\
\hline 54 & $42, \mathrm{~F}$ & T8-9 & GTR & amelanotic melanocytoma & - & - & - \\
\hline 55 & $51, \mathrm{M}$ & T1-2 & PR & metastasis (squamous cell carcinoma) & - & - & - \\
\hline
\end{tabular}

* $h$ = homogeneous; $i$ = inhomogeneous; - = none; + = vague; ++ = strong.

$\dagger$ A meningioma and an intramedullary ependymoma at the same level resected in one operation.

‡ Three hemangiopericytomas (2 WHO Grade II hemangiopericytomas, 1 WHO Grade III anaplastic hemangiopericytoma) resected in two operations.

study, we observed PpIX fluorescence in approximately half of the cases. Typical PpIX fluorescence was restricted to distinct histological spinal tumor entities in our series.

Spinal Ependymomas. Positive PpIX fluorescence occurred in all 12 ependymomas (Fig. 1). Similarly, Shimizu et al. first observed PpIX fluorescence in a patient with a spinal ependymoma. ${ }^{33}$ Similar findings were also recently reported in two other studies: Inoue et al. described the application of 5-ALA in 9 cases of spinal ependymomas, ${ }^{12}$ and positive PpIX fluorescence was observed in 7 of those 9 cases. Moreover, Eicker et al. investigated PpIX fluorescence in 26 patients with different intradural spinal tumors. ${ }^{5}$ In that study, positive PpIX fluorescence was observed in 1 of 2 myxopapillary ependymomas. ${ }^{5}$

Spinal Meningiomas. In our series, we found PpIX fluorescence in all 12 meningiomas (Figs. 1 and 2). Similarly, Eicker et al. observed PpIX fluorescence in 7 of 8 spinal meningiomas. ${ }^{5}$ Furthermore, Muroi et al. recently described the case of a meningioma in the cervical spine that showed strong PpIX fluorescence. ${ }^{23}$

Spinal Hemangiopericytomas. All 3 hemangiopericytomas in our study revealed positive PpIX fluorescence. To the best of our knowledge, this is the first observation of PpIX fluorescence in a spinal hemangiopericytoma.

Spinal Drop Metastases of CNS Tumors. Positive PpIX fluorescence was observed in 2 cases of spinal drop metastases of primary CNS tumors in our study. These 2 cases consisted of a glioblastoma and a papillary tumor of the pineal gland (Fig. 5). In line with the present study, Eicker et al. found PpIX fluorescence in all 4 cases of spinal drop metastases of primary cerebral malignant gliomas. ${ }^{5}$ Additionally, Rapp et al. reported 2 cases of drop metastases of primary cerebral malignant gliomas that showed positive PpIX fluorescence. ${ }^{28}$
These findings, including those from our current study, provide strong evidence that 5-ALA is a powerful tool for visualizing specific spinal tumors, such as ependymomas, meningiomas, hemangiopericytomas, and drop metastases of primary CNS tumors.

\section{Spinal Tumors With No Visible PpIX Fluorescence}

In contrast, none of the 8 neurinomas (Fig. 3), 5 carcinoma metastases, or 3 primary spinal gliomas (1 pilocytic astrocytoma, 1 WHO Grade II astrocytoma, 1 WHO Grade III anaplastic oligoastrocytoma) showed any PpIX fluorescence. Similarly, Eicker et al. reported that all 7 neurinomas included in their study were PpIX negative. ${ }^{5}$ In contrast to our findings, positive PpIX fluorescence was observed in a patient with a WHO Grade III intramedullary astrocytoma treated with palliative cordectomy. ${ }^{7}$ Note that 2 of the 3 primary spinal gliomas in our study were classified as low-grade gliomas.

To the best of our knowledge, this is the first report of 5-ALA in spinal carcinoma metastases. We could not detect PpIX fluorescence in any intratumoral part of our 5 cases.

\section{5-ALA for Detecting Residual Tumor Tissue}

We also investigated the value of 5-ALA-induced PpIX fluorescence for detecting potential residual tumor tissue in intramedullary neoplasms. It is notable that we were able to identify remaining fluorescing foci in 4 of 8 intramedullary ependymomas despite our impression of GTR under conventional white-light microscopy (Fig. 1). In all of these remaining fluorescing foci, tumor tissue was verified by histopathological examination. Furthermore, GTR was documented on postoperative MRI in each of these cases.

Shimizu et al. reported a similar case of remaining PpIX fluorescence in an intramedullary ependymoma. ${ }^{33}$ 

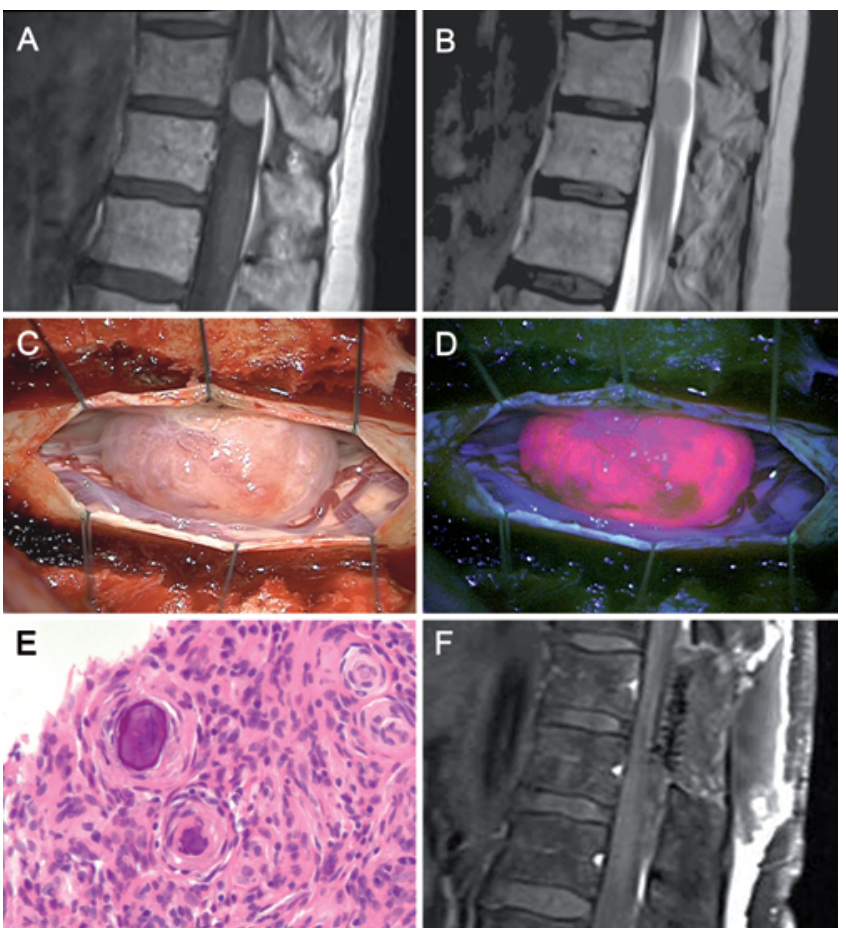

FIG. 2. Case 9. Visualization of a spinal meningioma with 5-ALA-induced PpIX fluorescence. Preoperative contrast-enhanced T1-weighted (A) and T2-weighted (B) MR images show an intradural extramedullary lesion (WHO Grade I meningioma) at the T-11 level. The meningioma has a typical macroscopic appearance under white-light (C) and strong and homogeneous PpIX fluorescence under violet-blue excitation light (D). Histopathological examination of the lesion reveals a WHO Grade I meningothelial meningioma (E). H \& E, original magnification $\times 40$. Postoperative MR image (F) confirms GTR of the meningioma.

After assumed GTR, these authors also removed an area of vague fluorescence that was detected by fluorescence spectrum analysis and was consistent with ependymoma tissue. Inoue et al. similarly described the resection of a PpIX fluorescing residual tumor in the case of an intramedullary ependymoma. ${ }^{12}$ Recently, the presence of small fluorescing tumor foci after assumed GTR was also described in 3 cases of spinal meningiomas. ${ }^{5,23}$ These independent observations highlight that 5-ALA-induced PpIX fluorescence is a promising technique for identifying small residual tumor foci that are not visible with conventional white-light microscopy.

In summary, our data indicate that intraoperative visualization of specific spinal tumor entities using 5-ALAinduced PpIX fluorescence is a clinically reliable method. The application of 5-ALA is useful especially in certain spinal tumor entities such as ependymomas, meningiomas, hemangiopericytomas, and drop metastases of primary CNS tumors. In contrast, in other histopathological tumor entities such as neurinomas and carcinoma metastases, the application of 5-ALA is of limited value according to our experience.

In cases of fluorescing intramedullary tumors, final inspection of the surgical cavity with violet-blue excitation light is a powerful technique for detecting potential residual tumor tissue. Additional resection of these small fluorescing foci using intraoperative neurophysiological
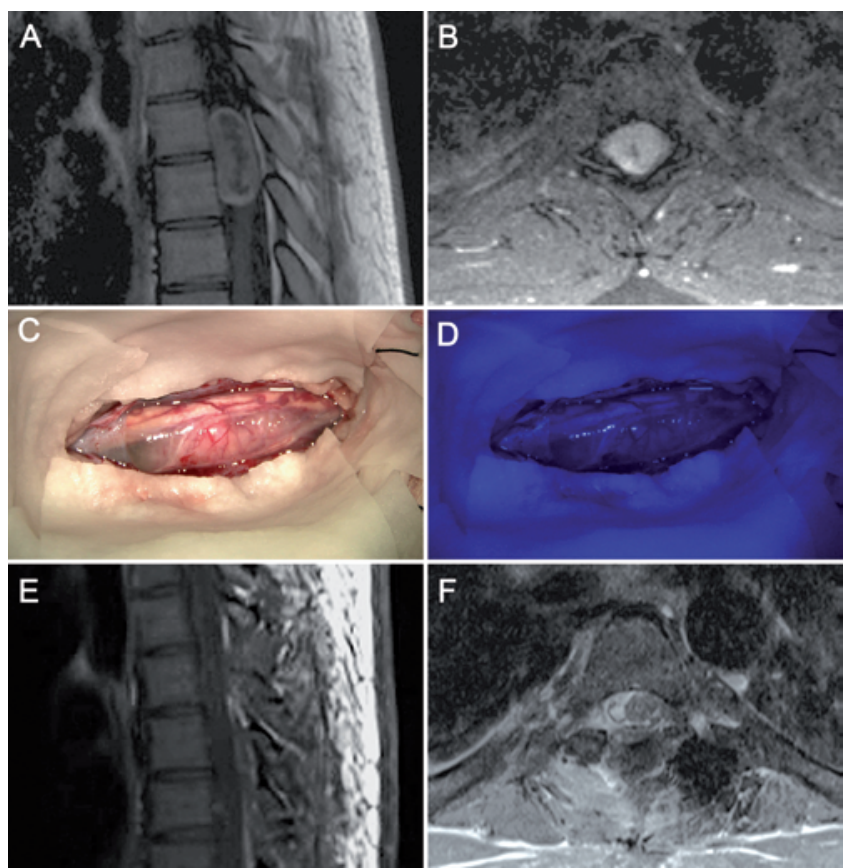

FIG. 3. Case 21. Spinal neurinoma with no visible PpIX fluorescence. Preoperative contrast-enhanced T1-weighted MR images (A and B) show a large intradural extramedullary tumor (WHO Grade I neurino$\mathrm{ma}$ ) at the T5-6 level. The neurinoma has a typical macroscopic appearance under white-light $(\mathbf{C})$ and no visible PpIX fluorescence in any intratumoral part under violet-blue excitation light (D). Postoperative MR images ( $E$ and $F$ ) show GTR of the neurinoma.

monitoring may increase the rate of GTR and thus minimize the risk of tumor recurrence.

These data define specific histopathological spinal tumor entities that are potential candidates for the intraoperative application of 5-ALA. Future studies should clarify the impact of PpIX fluorescence, especially in tumors with a high risk of incomplete resection such as diffusely infiltrating gliomas and some ependymomas without a clear cleavage plane.

\section{Future Directions}

Generally, PpIX fluorescence is classified as strong or vague based on the surgeon's perception. However, this semiquantitative analysis of PpIX fluorescence is observer-dependent, and thus vague fluorescence can be missed during surgery. Therefore, spectroscopic probes for quantitative assessment of PpIX fluorescence were introduced for neurosurgical procedures. ${ }^{8,40,41}$ With the use of such spectroscopic probes, small residual fluorescing foci can be more objectively identified. Furthermore, small amounts of PpIX accumulation were detected even in macroscopically nonfluorescing tumors. ${ }^{13,41}$ Therefore, visualization of macroscopically nonfluorescing tumor tissue using such spectroscopic probes may be a promising future approach.

\section{Conclusions}

Data in this observational study demonstrated that distinct spinal histopathological tumor entities can be 

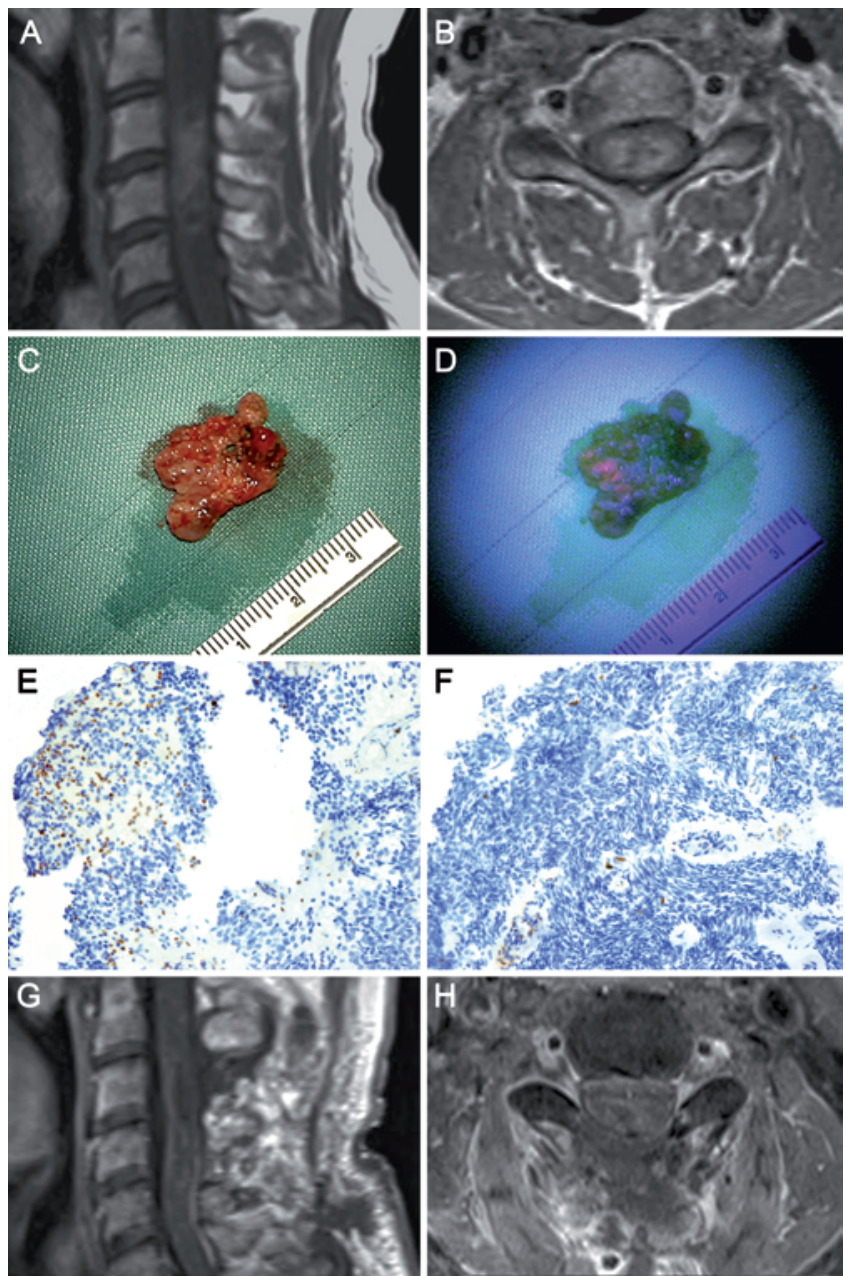

FIG. 4. Case 38. Spinal ependymoma with inhomogeneous PpIX fluorescence. Preoperative contrast-enhanced T1-weighted MR images (A and B) show an intramedullary lesion (WHO Grade II ependymoma) at the C3-4 level. White-light microscopy (C) depicts the typical ependymoma tissue (ex vivo specimen), which demonstrates inhomogeneous PpIX fluorescence that includes fluorescing and nonfluorescing areas under violet-blue excitation light (D). The tumor sample from the fluorescing area shows a high-proliferation rate (MIB-1: 17\%, E), whereas the tumor sample from the nonfluorescing area reveals a lowproliferation rate (MIB-1: $2 \%, \mathbf{F})$. Anti-Ki 67 , original magnification $\times 20$. Postoperative MR images ( $G$ and $H$ ) confirm GTR of the ependymoma.

visualized by 5-ALA-induced PpIX fluorescence. Positive PpIX fluorescence was especially observed in specific spinal tumors such as ependymomas, meningiomas, hemangiopericytomas, and drop metastases of primary
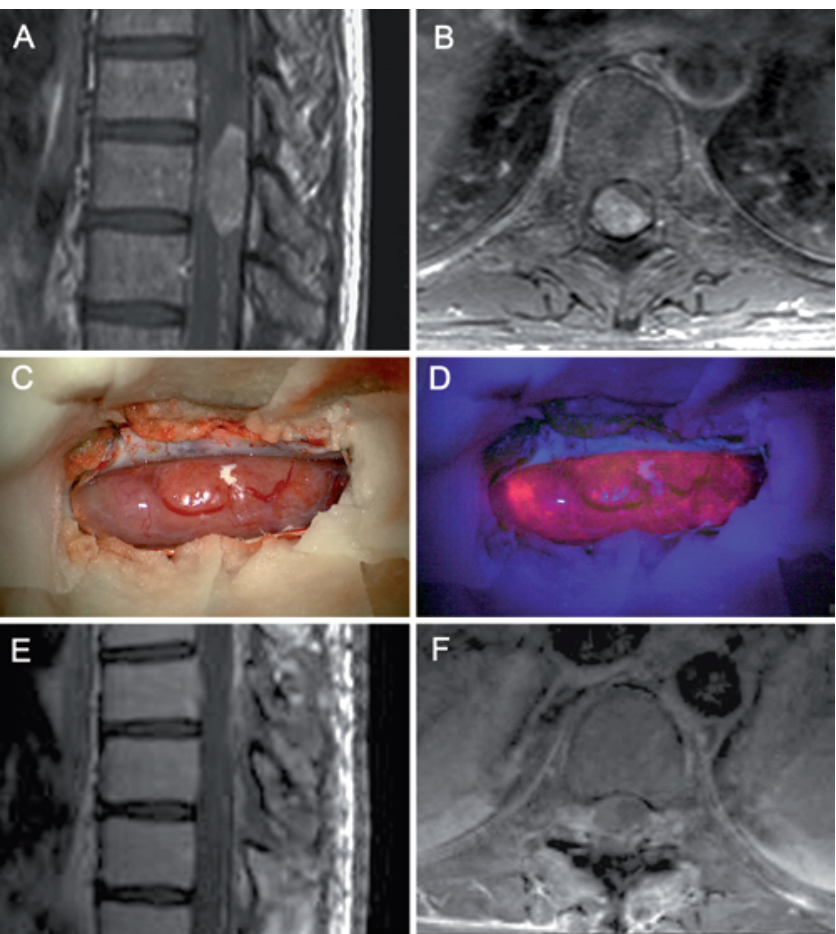

FIG. 5. Case 31. Visualization of a spinal drop metastasis of a papillary tumor of the pineal gland with 5-ALA-induced PpIX fluorescence. Preoperative contrast-enhanced T1-weighted MR images (A and B) show an intradural extramedullary lesion (drop metastasis of a papillary tumor of the pineal gland) with strong contrast-enhancement at the T8-9 level. White-light microscopy (C) reveals the drop metastasis, which shows strong and homogeneous PpIX fluorescence under violetblue excitation light (D). Postoperative MR images (E and F) confirm GTR of the drop metastasis.

CNS tumors. In contrast, in other specific spinal neoplasms, such as neurinomas and carcinoma metastases, no PpIX fluorescence was detected. In cases of fluorescing intramedullary tumors, 5-ALA-induced PpIX fluorescence represents a powerful tool for identifying potential residual tumors.

According to our data, 5-ALA could become a clinically reliable adjunct to current neurosurgical techniques in the management of spinal tumors.

\section{Disclosure}

The authors report no conflict of interest concerning the materials or methods used in this study or the findings specified in this paper. Dr. Wolfsberger is a consultant for Medtronic.

TABLE 4: Comparison of preoperative and postoperative McCormick grades*

\begin{tabular}{cccccc}
\hline & & \multicolumn{4}{c}{ McCormick Grade at Discharge } \\
\cline { 3 - 5 } Preop McCormick Grade & No. of Patients & I & II & III & IV \\
\hline I & 20 & 17 & 2 & 1 & 0 \\
II & 16 & 3 & 9 & 3 & 1 \\
III & 8 & 0 & 1 & 4 & 3 \\
IV & 8 & 0 & 1 & 1 & 6 \\
\hline
\end{tabular}

* Bold numbers indicate neurologically stable patients. 
Author contributions to the study and manuscript preparation include the following. Conception and design: Knosp, Millesi, Kiesel, Woehrer, Hainfellner, Wolfsberger, Widhalm. Acquisition of data: Millesi, Kiesel, Woehrer, Novak, Martínez-Moreno, Wolfsberger, Widhalm. Analysis and interpretation of data: all authors. Drafting the article: all authors. Critically revising the article: all authors. Reviewed submitted version of manuscript: all authors. Approved the final version of the manuscript on behalf of all authors: Knosp. Statistical analysis: Millesi, Kiesel, Wolfsberger, Widhalm. Administrative/technical/material support: Millesi, Kiesel, Novak, Wolfsberger, Widhalm. Study supervision: Knosp, Wolfsberger, Widhalm.

\section{References}

1. Benes V III, Barsa P, Benes V Jr, Suchomel P: Prognostic factors in intramedullary astrocytomas: a literature review. Eur Spine J 18:1397-1422, 2009

2. Chae MP, Song SW, Park SH, Park CK: Experience with 5-aminolevulinic acid in fluorescence-guided resection of a deep sylvian meningioma. J Korean Neurosurg Soc 52:558560,2012

3. Choi D, Crockard A, Bunger C, Harms J, Kawahara N, Mazel $\mathrm{C}$, et al: Review of metastatic spine tumour classification and indications for surgery: the consensus statement of the Global Spine Tumour Study Group. Eur Spine J 19:215-222, 2010

4. Coluccia D, Fandino J, Fujioka M, Cordovi S, Muroi C, Landolt $\mathrm{H}$ : Intraoperative 5-aminolevulinic-acid-induced fluorescence in meningiomas. Acta Neurochir (Wien) 152:1711-1719, 2010

5. Eicker SO, Floeth FW, Kamp M, Steiger HJ, Hänggi D: The impact of fluorescence guidance on spinal intradural tumour surgery. Eur Spine J 22:1394-1401, 2013

6. Engelhard HH, Villano JL, Porter KR, Stewart AK, Barua M, Barker FG II, et al: Clinical presentation, histology, and treatment in 430 patients with primary tumors of the spinal cord, spinal meninges, or cauda equina. Clinical article. J Neurosurg Spine 13:67-77, 2010

7. Ewelt C, Stummer W, Klink B, Felsberg J, Steiger HJ, Sabel $\mathrm{M}$ : Cordectomy as final treatment option for diffuse intramedullary malignant glioma using 5-ALA fluorescence-guided resection. Clin Neurol Neurosurg 112:357-361, 2010

8. Haj-Hosseini N, Richter J, Andersson-Engels S, Wårdell K: Optical touch pointer for fluorescence guided glioblastoma resection using 5-aminolevulinic acid. Lasers Surg Med 42:9-14, 2010

9. Halvorsen CM, Kolstad F, Hald J, Johannesen TB, Krossnes BK, Langmoen IA, et al: Long-term outcome after resection of intraspinal ependymomas: report of 86 consecutive cases. Neurosurgery 67:1622-1631, 2010

10. Hanbali F, Fourney DR, Marmor E, Suki D, Rhines LD, Weinberg JS, et al: Spinal cord ependymoma: radical surgical resection and outcome. Neurosurgery 51:1162-1174, 2002

11. Hsu S, Quattrone M, Ostrom Q, Ryken TC, Sloan AE, Barnholtz-Sloan JS: Incidence patterns for primary malignant spinal cord gliomas: a Surveillance, Epidemiology, and End Results study. Clinical article. J Neurosurg Spine 14:742-747, 2011

12. Inoue $T$, Endo $T$, Nagamatsu $K$, Watanabe $M$, Tominaga $T$ : 5-aminolevulinic acid fluorescence-guided resection of intramedullary ependymoma: report of 9 cases. Neurosurgery 72 (2 Suppl Operative):159-168, 2012

13. Ishihara R, Katayama Y, Watanabe T, Yoshino A, Fukushima T, Sakatani K: Quantitative spectroscopic analysis of 5-aminolevulinic acid-induced protoporphyrin IX fluorescence intensity in diffusely infiltrating astrocytomas. Neurol Med Chir (Tokyo) 47:53-57, 2007

14. Kajimoto Y, Kuroiwa T, Miyatake SI, Ichioka T, Miyashita M, Tanaka H, et al: Use of 5-aminolevulinic acid in fluorescenceguided resection of meningioma with high risk of recurrence. Case report. J Neurosurg 106:1070-1074, 2007
15. Kamp MA, Grosser P, Felsberg J, Slotty PJ, Steiger HJ, Reifenberger G, et al: 5-aminolevulinic acid (5-ALA)-induced fluorescence in intracerebral metastases: a retrospective study. Acta Neurochir (Wien) 154:223-228, 2011

16. Klekamp J: Treatment of intramedullary tumors: analysis of surgical morbidity and long-term results. Clinical article. J Neurosurg Spine 19:12-26, 2013

17. Kucia EJ, Bambakidis NC, Chang SW, Spetzler RF: Surgical technique and outcomes in the treatment of spinal cord ependymomas, part 1: intramedullary ependymomas. Neurosurgery 68 (1 Suppl Operative):57-63, 2011

18. Louis DN, Ohgaki H, Wiestler OD, Cavenee WK: WHO Classification of Tumours of the Central Nervous System. Lyon: IARC Press, 2007

19. McCormick PC, Torres R, Post KD, Stein BM: Intramedullary ependymoma of the spinal cord. J Neurosurg 72:523-532, 1990

20. McGirt MJ, Goldstein IM, Chaichana KL, Tobias ME, Kothbauer KF, Jallo GI: Extent of surgical resection of malignant malignant astrocytomas of the spinal cord: outcome analysis of 35 patients. Neurosurgery 63:55-61, 2008

21. Moon KY, Chung CK, Jahng TA, Kim HJ, Kim CH: Postoperative survival and ambulatory outcome in metastatic spinal tumors: prognostic factor analysis. J Korean Neurosurg Soc 50:216-223, 2011

22. Moore GE, Peyton WT, French LA, Walker WW: The clinical use of fluorescein in neurosurgery. The localization of brain tumors. J Neurosurg 5:392-398, 1948

23. Muroi C, Fandino J, Coluccia D, Berkmann S, Fathi AR, Landolt H: 5-aminolevulinic acid fluorescence-guided surgery for spinal meningioma. World Neurosurg 80:223.e1223.e3, 2012

24. Mut M, Schiff D, Shaffrey ME: Metastasis to nervous system: spinal epidural and intramedullary metastases. J Neurooncol 75:43-56, 2005

25. Nagpal S, Clarke JL: Neoplastic myelopathy. Semin Neurol 32:137-145, 2012

26. Novak K, Widhalm G, de Camargo AB, Perin N, Jallo G, Knosp E, et al: The value of intraoperative motor evoked potential monitoring during surgical intervention for thoracic idiopathic spinal cord herniation. Clinical article. J Neurosurg Spine 16:114-126, 2012

27. Obwegeser A, Jakober R, Kostron H: Uptake and kinetics of $14 \mathrm{C}$-labelled meta-tetrahydroxyphenylchlorin and 5-aminolaevulinic acid in the C6 rat glioma model. Br J Cancer 78:733-738, 1998

28. Rapp M, Klingenhöfer M, Felsberg J, Steiger HJ, Stummer W, Sabel M: Fluorescence-guided resection of spinal metastases of malignant glioma: report of 2 cases. J Neurol Surg A Cent Eur Neurosurg 73:103-105, 2011

29. Regelsberger J, Fritzsche E, Langer N, Westphal M: Intraoperative sonography of intra- and extramedullary tumors. Ultrasound Med Biol 31:593-598, 2005

30. Sala F, Palandri G, Basso E, Lanteri P, Deletis V, Faccioli F, et al: Motor evoked potential monitoring improves outcome after surgery for intramedullary spinal cord tumors: a historical control study. Neurosurgery 58:1129-1143, 2006

31. Schellinger KA, Propp JM, Villano JL, McCarthy BJ: Descriptive epidemiology of primary spinal cord tumors. J Neurooncol 87:173-179, 2008

32. Schwartz TH, McCormick PC: Intramedullary ependymomas: clinical presentation, surgical treatment strategies and prognosis. J Neurooncol 47:211-218, 2000

33. Shimizu S, Utsuki S, Sato K, Oka H, Fujii K, Mii K: Photodynamic diagnosis in surgery for spinal ependymoma. Case illustration. J Neurosurg Spine 5:380, 2006

34. Stummer W, Novotny A, Stepp H, Goetz C, Bise K, Reulen HJ: Fluorescence-guided resection of glioblastoma multiforme by using 5-aminolevulinic acid-induced porphyrins: a 


\section{5-ALA in spinal tumors}

prospective study in 52 consecutive patients. J Neurosurg 93: 1003-1013, 2000

35. Stummer W, Pichlmeier U, Meinel T, Wiestler OD, Zanella F, Reulen HJ: Fluorescence-guided surgery with 5-aminolevulinic acid for resection of malignant glioma: a randomised controlled multicentre phase III trial. Lancet Oncol 7:392401, 2006

36. Stummer W, Stepp H, Möller G, Ehrhardt A, Leonhard M, Reulen HJ: Technical principles for protoporphyrin-IX-fluorescence guided microsurgical resection of malignant glioma tissue. Acta Neurochir (Wien) 140:995-1000, 1998

37. Stummer W, Stocker S, Novotny A, Heimann A, Sauer O, Kempski O, et al: In vitro and in vivo porphyrin accumulation by C6 glioma cells after exposure to 5-aminolevulinic acid. J Photochem Photobiol B 45:160-169, 1998

38. Stummer W, Stocker S, Wagner S, Stepp H, Fritsch C, Goetz $\mathrm{C}$, et al: Intraoperative detection of malignant gliomas by 5 -aminolevulinic acid-induced porphyrin fluorescence. Neurosurgery 42:518-526, 1998

39. Tarapore PE, Modera P, Naujokas A, Oh MC, Amin B, Tihan T, et al: Pathology of spinal ependymomas: an institutional experience over 25 years in 134 patients. Neurosurgery 73: 247-255, 2013

40. Valdés PA, Bekelis K, Harris BT, Wilson BC, Leblond F, Kim A, et al: 5-aminolevulinic-acid-induced protoporphyrin IX fluorescence in meningioma: qualitative and quantitative measurements in vivo. Neurosurgery [epub ahead of print], 2013

41. Valdés PA, Leblond F, Kim A, Harris BT, Wilson BC, Fan X, et al: Quantitative fluorescence in intracranial tumor: implications for ALA-induced PpIX as an intraoperative biomarker. Clinical article. J Neurosurg 115:11-17, 2011

42. Van Goethem JW, van den Hauwe L, Ozsarlak O, De Schepper AM, Parizel PM: Spinal tumors. Eur J Radiol 50:159176, 2004
43. Widhalm G, Kiesel B, Woehrer A, Traub-Weidinger T, Preusser M, Marosi C, et al: 5-aminolevulinic acid induced fluorescence is a powerful intraoperative marker for precise histopathological grading of diffusely infiltrating gliomas. PLoS ONE 8:e76988, 2013

44. Widhalm G, Minchev G, Woehrer A, Preusser M, Kiesel B, Furtner J, et al: Strong 5-aminolevulinic acid-induced fluorescence is a novel intraoperative marker for representative tissue samples in stereotactic brain tumor biopsies. Neurosurg Rev 35:381-391, 2012

45. Widhalm G, Wolfsberger S, Minchev G, Woehrer A, Krssak M, Czech T, et al: 5-Aminolevulinic acid is a promising marker for detection of anaplastic foci in diffusely infiltrating gliomas with nonsignificant contrast enhancement. Cancer 116:1545-1552, 2010

46. Yang S, Yang X, Hong G: Surgical treatment of one hundred seventy-four intramedullary spinal cord tumors. Spine (Phila Pa 1976) 34:2705-2710, 2009

47. Zhou H, Miller D, Schulte DM, Benes L, Bozinov O, Sure U, et al: Intraoperative ultrasound assistance in treatment of intradural spinal tumours. Clin Neurol Neurosurg 113:531-537, 2011

Manuscript submitted October 15, 2013.

Accepted December 10, 2013.

Please include this information when citing this paper: DOI: 10.3171/2013.12.FOCUS13485.

Address correspondence to: Engelbert Knosp, M.D., Department of Neurosurgery, Medical University of Vienna, Comprehensive Cancer Center-Central Nervous System Tumours Unit (CCC-CNS), Waehringer Guertel 18-20, 1097 Vienna, Austria. email: engelbert. knosp@meduniwien.ac.at. 